Original article

\title{
Impact of COVID-19 pandemic on mental health, risk perception and coping strategies among health care workers in Albania - evidence that needs attention
}

\author{
Fatjona Kamberi $^{\mathrm{a},{ }^{*}, \text { Enkeleda Sinaj }}{ }^{\mathrm{b}}$, Jerina Jaho ${ }^{\mathrm{a}}$, Brunilda Subashi ${ }^{\mathrm{a}}$, Glodiana Sinanaj ${ }^{\mathrm{a}}$, \\ Kristela Jaupaj ${ }^{\mathrm{a}}$, Yllka Stramarko ${ }^{\mathrm{a}}$, Paola Arapi ${ }^{\mathrm{c}}$, Ledia Dine ${ }^{\mathrm{c}}$, Arberesha Gurguri ${ }^{\mathrm{d}}$, \\ Juljana Xhindoli ${ }^{\mathrm{e}}$, Jorgjie Bucaj ${ }^{\mathrm{e}}$, Lorena Alikaj Serjanaj ${ }^{\mathrm{f}}$, Roy Rillera Marzo ${ }^{\mathrm{g}}$, \\ Mila $\mathrm{Nu} \mathrm{Nu}$ Htay $^{\mathrm{h}}$
}

${ }^{a}$ Research Centre of Public Health, Faculty of Health, University of Vlore "Ismail Qemali", Vlore, Albania

${ }^{\mathrm{b}}$ Department of Physiotherapy, Faculty of Technical Medical Sciences, University of Medicine Tirana, Albania

" University Medical Center of Tirana "Mother Teresa", Tirana, Albania

d Department of Nursing, Faculty of Health, University of Vlore "Ismail Qemali", Vlore, Albania

e Department of Health Care, Faculty of Health, University of Vlore "Ismail Qemali", Vlore, Albania

${ }^{\mathrm{f}}$ Department of Economics, Faculty of Economy, University of Vlore"Ismail Qemali", Vlore, Albania

${ }^{g}$ Department of Public Health, Faculty of Medicine, Asia Metropolitan University, Johor, Malaysia

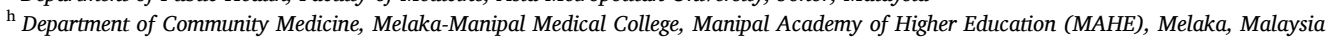

\section{A R T I C L E I N F O}

\section{Keywords:}

COVID-19

Impact

Mental health

Health care workers

First wave

Albania

\begin{abstract}
A B S T R A C T
Background: The COVID-19 pandemic impacted health care workers in many ways including mental health. This impact is usually underestimated in particular in developing countries.

Objectives: The study aims to assess the level of anxiety, depression, risk perception, and coping strategies of Albanian healthcare workers during the COVID-19 pandemic and to identify associated factors.

Methods: A cross-sectional online study was conducted from April to May 2020 by recruiting health care personnel through the snowballing method. Data collection was carried out through social media using the Generalized Anxiety Disorder (GAD-7) scale and Patient Health Questionnaire (PHQ-9) by Google forms. Participants were recruited from all health care sectors including doctors, nurses, etc. working in both the public and private sectors.

Results: 410 questionnaires were included in the analysis. Most participants were nurses (59.3\%), female (78.5\%), and belonged to the age group 26-40 years (46.3\%). Mild levels of anxiety were expressed in $26.9 \%$ of participants while $7.2 \%$ of them expressed moderate levels. $23.1 \%$ and $12.1 \%$ of participants expressed respectively mild and moderate depression levels. High levels of risk perception were found. A statistical association was found between occupation $(p=0.011)$, gender $(p=0.031)$, providing care for COVID-19 patients ( $p$ $=0.011$ ), and the availably of mental health support in the workplace. Poor coping strategies were reported among participants.

Conclusions: Mental health support should be a priority of the healthcare system in particular for young health care workers caring for COVID-19 patients. It can improve the mental health status of health care workers and their family members, impacting the quality of care provided.
\end{abstract}

\section{Introduction}

On 11 March 2020, the World Health Organization (WHO) declared the state of a pandemic due to SARS-CoV2 or COVID-19 outbreak $^{1}$ first detected in Wuhan City, Hubei Province, China in late December 2019. ${ }^{2}$ The virus is transmitted human-to human among close contacts ${ }^{3}$ and all patients have an acute respiratory distress syndrome with pneumonia characterized by abnormal findings on chest Computed Tomography. ${ }^{4}$

\footnotetext{
* Corresponding author.

E-mail address: fatjona.kamberi@univlora.edu.al (F. Kamberi).
} 
Studies suggest that healthcare workers are at higher risk of infection when treating patients with COVID-19. ${ }^{5},{ }^{6}$ They are also vulnerable to physical and emotional exhaustion ${ }^{7}$ as well as the development of various mental health disorders ${ }^{8}$ a fact confirmed by the higher grades of mental health symptoms reported throughout the pandemic. ${ }^{9}$ In Albania, the first case of coronavirus was confirmed on March 9, 2020, while the number of total positive COVID-19 cases in late March was 64 .

${ }^{10}$ As of July 13, 2020, Albania recorded 3454 cases of coronavirus ${ }^{11}$ and 93 deaths. ${ }^{12}$ According to the data published daily on the Albanian Ministry of Health's website the city most affected was Tirana (the capital) with 591 cases and 47 deaths, followed by Durres and Shkodra respectively with 229 and 178 cases and 14 deaths each, and Vlora with 120 cases and 2 deaths. Among those infected or dead are health care workers, aligning with worldwide data. ${ }^{13}$ The pandemic has increased fear among healthcare workers worldwide for themselves, their families, colleagues, and the community impacting their mental wellbeing. ${ }^{14}$ The impact of the COVID-19 outbreak on the mental health of healthcare workers has been reported in some countries. For example. a study using the Generalized Anxiety Disorder (GAD-7) Anxiety Severity screening tool for data collection found higher levels of stress and anxiety among healthcare workers. ${ }^{15}$ This is particularly true for female and front-line health care workers, who stressed the importance of psychological support. ${ }^{16},{ }^{17}$ Further research suggests that the mental health support of healthcare workers should be a priority in order to combat the emerging mental health issues with impacted healthcare personnel worldwide, emphasizing the role of targeted interventions. ${ }^{18,19,20,21,22,23}$ Despite the above-mentioned findings, currently, there are few scientific studies addressing the impact of COVID-19 on the mental health of health care workers in the Western Balkan Countries, including Albania. In addition, as reported by WHO, in Albania from 3 January 2020 to 31 March 2021 there have been 124,723 confirmed cases of COVID-19 with 2227 deaths. ${ }^{24}$ There is still a lack of scientific knowledge about risk factors, support systems, and coping strategies in countries and areas with insufficient health care resources. To our best knowledge, this study is the first to include international cooperation with the objective of evaluating the impact of the COVID-19 pandemic on mental health, risk perception, and coping strategies among health care workers in Albania.

\section{Methods}

\subsection{Study design}

The cross-sectional online study was conducted by recruiting health care personnel living in Albania through the snowballing method. Data collection was carried out through the social media (Twitter, Facebook, email, etc.) of the Albanian authors using Google forms. It should be emphasized that the authors are health care professionals who have been previously engaged in clinical practice. Repeated posts including a survey form were made until the desired sample size was reached. The sample size was calculated based on sample size calculations in crosssectional medical studies with a $95 \%$ confidence interval, and $5 \%$ precision. ${ }^{25}$ Based on the above the estimated sample size is 385 . The participants' consent was obtained before initiating the questions. They could begin filling the survey only after being presented a short informative text on the objectives of the study and agreeing to participate. Participation was voluntary and confidentiality was ascertained. Every participant could complete the questionnaire once. The data collection was conducted during a one-month period from April 20th, 2020 to May 20th, 2020, which coincides with the first wave of the pandemic in Albania. Participants were recruited from all health care sectors including doctors, nurses, medical assistants, laboratory technicians, and public health practitioners, working in both the public and private sector. Ethical approval was granted from the Research Ethics Committee of Asia Metropolitan University (AMU), Project Ref No: AMU
/MREC/FOM/NF/03/2020. In addition, the ethical committee of the Faculty of Health, University of Vlore, Albania was informed and approved of the study.

\subsection{Research objectives}

This study aims to assess the levels of anxiety, depression, risk perception, and coping strategies of Albanian healthcare workers during the COVID-19 pandemic and to identify demographic factors associated with mental health issues.

\subsection{Study variables}

The study variables include sociodemographic data, anxiety and depression levels, risk perception, and coping strategies.

\subsubsection{Demographic variables}

Age (used as a continuous variable), gender, religion, marital and living status, work experience, and current workplace and occupation (doctors, nurses, and others, including medical assistants, laboratory technicians, pharmacists, research scientists, etc.)

\subsubsection{Anxiety variables}

The Generalized Anxiety Disorder 7-item (GAD-7) questionnaire ${ }^{26}$ was used to assess anxiety levels among participants. Responses were recorded as "Not at all $=0$ ", "Several days $=1$ ", "More than half of the days $=2$ ", "Nearly every day $=3$ ". GAD-7 was not available in the Albanian language. The questionnaire was translated and reconciled in Albanian through a pilot study the results of which were not included in the final analysis.

\subsubsection{Depression variables}

The 9-item Patient Health Questionnaire (PHQ-9) ${ }^{27}$ was used to assess depression levels. PHQ-9 is used as part of Basic Medical Control for Albanian Citizens so a translated version was already available. The responses were recorded as "Not at all $=0$ ", "Several days $=1$ ", "More than half of the days $=2$ ", "Nearly every day $=3$ ".

\subsubsection{Risk perception and coping strategy variables}

The risk perception of the participants was assessed by using 6 items. Coping strategies were assessed with 3 items. The responses were recorded as "Agree = 2", "Neutral =1" and "Disagree =0", except for one item of coping strategy, which was an open-ended question.

\subsection{Statistical analysis}

The statistical software Stata and IBM SPSS Statistics 25 were used to analyse the data. Descriptive statistics expressed in frequencies and percentages were used for sociodemographic variables. The GAD-7 total scoring was calculated and classified anxiety levels as; Normal (0-4), mild (5-9), moderate (10-14), and severe (15-21). The PHQ-9 total scoring was calculated and classified the level of depression as Normal (0-4), Mild (5-9), Moderate (10-14), moderately severe (15-19), and Severe (20-27). The individual item mean scores and the total mean score (range: $0-12$ ) were calculated. The participants who had scores higher than the cut-off point were considered to have severe symptoms. ${ }^{8}$ The participants' coping strategies were enquired and analysed with descriptive statistics. The internal consistency of the scales was assessed with Cronbach's alpha. 2-tailed $\mathrm{p}$ was used to test the association among variables. $P$ values $\leq 0.05$ were considered statistically significant. The factors associated with anxiety and depression were assessed using logistic regression analysis. The cut-off score for having generalized anxiety disorder symptoms and depression symptoms is for both $10 .{ }^{28}$ 
Table 1

Socio-demographic characteristics and occupation of participants $(n=410)$.

\begin{tabular}{|c|c|c|c|c|}
\hline \multirow[t]{2}{*}{ Demographic characteristics } & \multicolumn{3}{|l|}{ Occupation } & \multirow[t]{2}{*}{ Total n (\%) } \\
\hline & Doctors (\%) & Nurses (\%) & Others $^{\mathrm{a}}(\%)$ & \\
\hline Gender & 10.7 & 59.3 & 30.0 & $410(100)$ \\
\hline Total & 20.5 & 16.9 & 16.5 & $67(16.3)$ \\
\hline Male & 79.5 & 83.1 & 82.5 & $322(78.5)$ \\
\hline \multicolumn{5}{|l|}{ Female } \\
\hline Age (years) & 15.9 & 22.6 & 58.3 & $120(30.9)$ \\
\hline$\leq 25$ & 54.5 & 52.3 & 28.2 & $180(46.3)$ \\
\hline $26-40$ & 25.0 & 24.3 & 12.6 & $83(20.8)$ \\
\hline $41-60$ & 4.5 & 24.3 & 1.0 & $5(2.0)$ \\
\hline \multicolumn{5}{|l|}{$\geq 61$} \\
\hline Religion & 34.1 & 23.9 & 29.1 & $101(24.6)$ \\
\hline Christianity & 50.0 & 65.8 & 56.3 & $240(58.5)$ \\
\hline Muslim & 15.9 & 10.3 & 14.6 & $45(16.8)$ \\
\hline \multicolumn{5}{|l|}{ Others } \\
\hline Marital status & 40.9 & 64.6 & 32.0 & $208(50.7)$ \\
\hline Married & 59.1 & 35.4 & 68.0 & $202(49.3)$ \\
\hline \multicolumn{5}{|l|}{ Single $\mathrm{e}^{\mathrm{b}}$} \\
\hline Living status & 88.6 & 92.2 & 87.4 & $353(86.1)$ \\
\hline Family & 0.0 & 1.2 & 2.9 & $6(1.5)$ \\
\hline Friends & 11.4 & 6.6 & 9.7 & $27(6.6)$ \\
\hline \multicolumn{5}{|l|}{ Alone } \\
\hline Working experience (years) & 40.9 & 32.9 & 57.3 & $175(42.7)$ \\
\hline$<2$ & 15.9 & 14.8 & 13.6 & $56(13.6)$ \\
\hline $2-5$ & 4.5 & 14.0 & 13.6 & $67(16.3)$ \\
\hline $6-10$ & 38.6 & 38.3 & 15.5 & $112(27.4)$ \\
\hline \multicolumn{5}{|l|}{$>10$} \\
\hline Current workplace & 45.5 & 53.5 & 9.7 & $160(39.0)$ \\
\hline Hospitals & 31.8 & 11.5 & 1.9 & $44(10.7)$ \\
\hline Clinics & 0.0 & 0.0 & 7.8 & $8(2.0)$ \\
\hline Laboratory & 22.7 & 35.0 & 80.6 & $198(48.3)$ \\
\hline \multicolumn{5}{|l|}{ Others ${ }^{\mathrm{c}}$} \\
\hline Working position (Providing direct healthcare to patients) & 84.1 & 80.2 & 27.2 & $260(63.4)$ \\
\hline Yes & 15.9 & 19.8 & 72.8 & $119(29.0)$ \\
\hline \multicolumn{5}{|l|}{ No } \\
\hline Providing healthcare to COVID-19 cases (suspected or confirmed) & 40.9 & 26.3 & 16.5 & $119(29.0)$ \\
\hline Yes & 59.1 & 73.7 & 83.5 & $260(63.4)$ \\
\hline \multicolumn{5}{|l|}{ No } \\
\hline Mental health services available at workplace & 29.5 & 33.3 & 35.0 & $40(9.8)$ \\
\hline Yes & 70.5 & 66.7 & 65.0 & $333(81.2)$ \\
\hline \multicolumn{5}{|l|}{ No } \\
\hline Support from mental health support team at workplace & 6.8 & 10.3 & 11.7 & $130(31.7)$ \\
\hline Yes & 93.2 & 89.7 & 88.3 & $243(59.3)$ \\
\hline No & & & & \\
\hline
\end{tabular}

a Others (occupation) included medical assistants, laboratory technicians, pharmacists, research scientists, etc.

b Participants who are widowed, divorced and who never married.

c Others (workplace) included pharmacy, public health office, research institute, medical university, etc.

\section{Results}

\subsection{Demographic characteristics of the study population, $n=410$}

The survey was completed by 420 participants in total, but due to errors in completion and some incomplete sections, only 410 questionnaires were included in the final statistical analysis. Most of the study population were nurses $(59.3 \%)$, female $(78.5 \%)$, and belonged to the age group 26-40 years (46.3\%), Table 1 . Among the study sample, $58.5 \%$ reported being Muslim and $50.7 \%$ of participants were married. Most of the health care workers in the study (86.1\%) lived with their families. $42.7 \%$ of them had $<2$ years of working experience and $27.4 \%$ had $>10$ years of working experience. The majority of participants (39.0\%) declared that their current workplace is a hospital. $63.4 \%$ work directly with patients and $29.0 \%$ provide health care for suspected or confirmed COVID-19 patients. $81.2 \%$ of healthcare workers in the study reported a lack of mental health services in the workplace as well as a lack of a mental support team (59.3\%).

\subsection{Anxiety variables (GAD-7 total scoring and reliability statistics)}

used to assess levels of anxiety. Mild levels of anxiety were expressed by $26.9 \%$ of study participants while $7.2 \%$ of them expressed moderate levels. Based on occupation, doctors (34.1\%) and nurses (26.9\%) reported mild levels of anxiety. No statistical association was found between occupation, providing healthcare to COVID-19 patients, and anxiety levels, $\mathrm{p}>0.05$, Table 2 . It is found that male healthcare workers expressed mild (27.9\%) and moderate (8.8\%) levels of anxiety in a higher percentage compared to female healthcare workers.

\subsection{Depression variables (PHQ-9 total scoring and reliability statistics)}

The PHQ-9 total scoring calculation, Table 2 found that $23.1 \%$ of participants had mild depression levels and $12.1 \%$ moderate. These levels were higher among doctors in comparison to nurses. In addition, a statistical correlation was found between occupation and depression levels, $\mathrm{p}=0.000, \mathrm{p}=0.004, \mathrm{p}=0.010$. No statistical association was found between PHQ-9 score and gender. The normal status of depression was statistically associated with direct care for COVID-19 patients, $\mathrm{p}=$ 0.048 . 
Table 2

Anxiety, depression, risk perception levels and coping strategies among healthcare workers, 2-tailed p value.

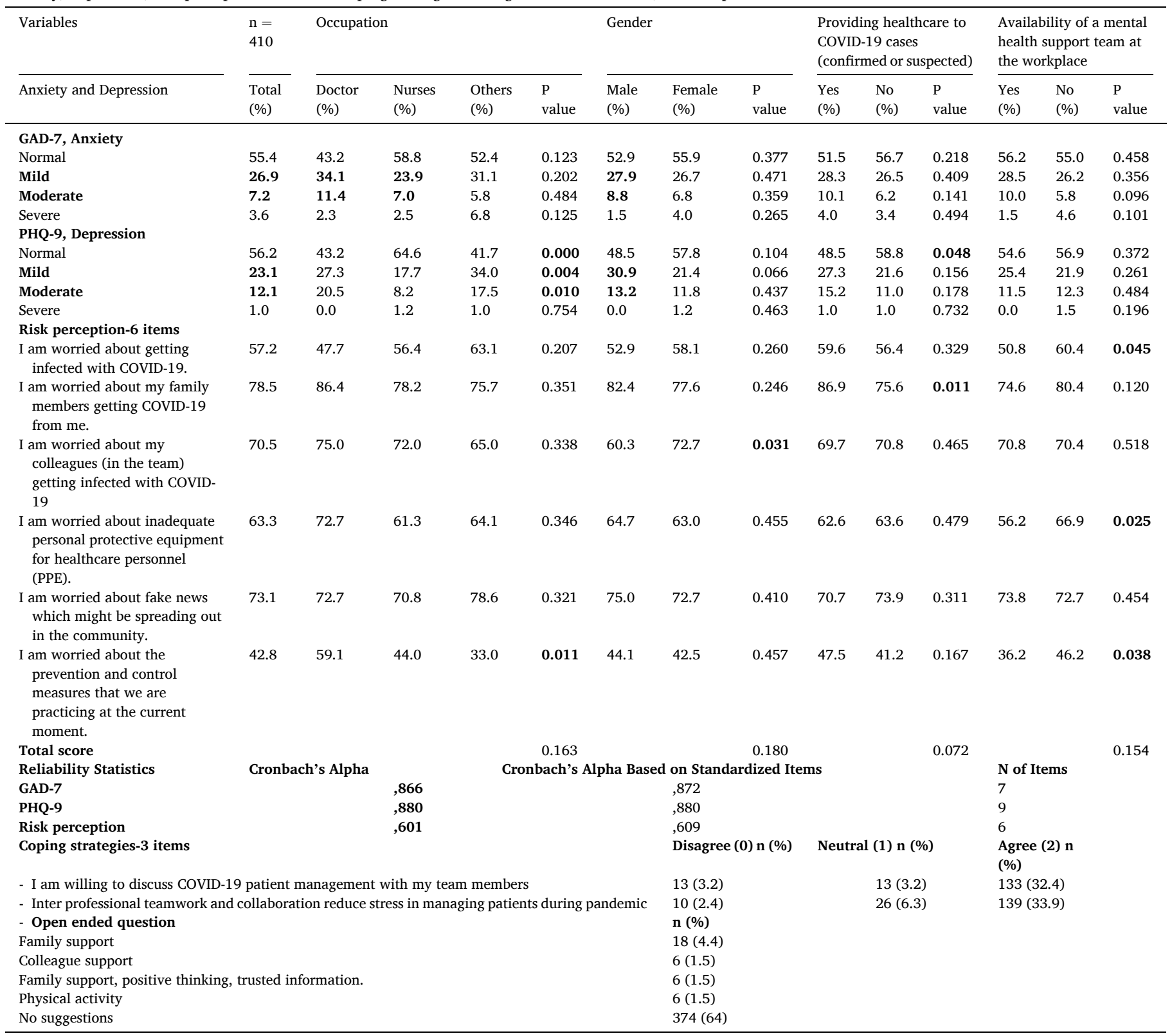

\subsection{Risk perception (total scoring and reliability statistics)}

The total score of risk perception shows high levels of risk perception (up to 50\%) among health care workers for all 6-items. A statistical association was found between occupation $(p=0.011)$, gender $(p=$ $0.031)$, providing care for COVID-19 patients $(\mathrm{p}=0.011)$, and the availably of a mental health support team in the workplace $(\mathrm{p}=0.045$, $\mathrm{p}=0.025, \mathrm{p}=0.038$ ) and different items of risk perception, Table 2 .

\subsection{Coping strategies (frequency and percentage)}

The results in Table 2 show that $32.4 \%$ of healthcare workers in the study agree to discuss the management of the situation with the health care team. $33.9 \%$ reported that collaboration and interprofessional teamwork help reduce stress. The open-ended question shows that the majority (64\%) of study participants do not have any suggestion for how to cope with stress during the pandemic.
3.6. Factors associated with anxiety and depression among healthcare workers (linear regression)

Table 3 shows the association of socio-demographic data with the levels of anxiety and depression. As seen, symptoms of anxiety were associated with age, marital and living status. Symptoms of depression were associated with living status, workplace, and support from the mental health team at the workplace.

\section{Discussion}

To our best knowledge, this is the first research study in Albania and among the few focused on the effect of the pandemic on the mental health of health care workers in a Western Balkan Country. Different review studies have highlighted that the mental health of health care workers during the COVID-19 pandemic must be addressed. ${ }^{29,30,31}$ The analysis of data from 410 participants found a high impact of the COVID-19 pandemic on the mental health of health care workers. The 
Table 3

Factors associated with anxiety and depression among the healthcare workers (linear regression).

\begin{tabular}{|c|c|c|c|c|c|c|c|c|c|}
\hline \multirow[t]{2}{*}{ Variables } & \multicolumn{5}{|l|}{ Anxiety $^{a}$} & \multicolumn{4}{|l|}{ Depression $^{\mathrm{b}}$} \\
\hline & Coefficients & Odds ratio & $\mathrm{P}>|\mathrm{z}|$ & & & Coefficients & & Odds ratio & $P>|z|$ \\
\hline \multicolumn{10}{|l|}{ Constant $-15.342 .160 .0002 .0467 .70 .119$} \\
\hline \multicolumn{10}{|c|}{0.9739} \\
\hline \multicolumn{10}{|l|}{ Gender } \\
\hline Male & -0.0263 & 0.9739 & 0.945 & & & -0.3403 & 0.7 & & 0.366 \\
\hline Female & 0 & 1 & & & & 0 & 1 & & \\
\hline \multicolumn{10}{|l|}{ Age (years) } \\
\hline$\leq 25$ & 14.854 & 282626 & 0.000 & & & -1.7514 & 0.2 & & 0.119 \\
\hline $26-40$ & 14.560 & 210692 & 0.000 & & & -1.6214 & 0.2 & & 0.141 \\
\hline $41-60$ & 14.859 & 284138 & 0.000 & & & -1.8833 & 0.2 & & 0.103 \\
\hline$\geq 61$ & 0 & 1 & & & & & & & \\
\hline \multicolumn{10}{|l|}{ Religion } \\
\hline Christianity & 0.1215 & 1.1292 & 0.801 & & & -0.6354 & 0.5 & & 0.176 \\
\hline Islam & -0.294 & 0.7448 & 0.492 & & & -0.2816 & 0.8 & & 0.479 \\
\hline Others & 0 & 1 & & & & 0 & 1 & & \\
\hline \multicolumn{10}{|l|}{ Marital status } \\
\hline Married & 0.6689 & 1.9521 & 0.049 & & & 0.2487 & 1.3 & & 0.459 \\
\hline Single $e^{c}$ & 0 & 1 & & & & 0 & 1 & & \\
\hline \multicolumn{10}{|l|}{ Living status } \\
\hline Family & -1.3928 & 0.2483 & 0.002 & & -1.2393 & & 0.3 & & 0.008 \\
\hline Friends & -0.5066 & 0.6025 & 0.674 & & -0.6665 & & 0.5 & & 0.484 \\
\hline Alone & 0 & 1 & & & 0 & & 1 & & \\
\hline \multicolumn{10}{|l|}{ Occupation } \\
\hline Doctors & 0.4946 & 1.6398 & 0.356 & & 0.0484 & & 1.0 & & 0.924 \\
\hline Nurses & 0.0977 & 1.1027 & 0.798 & & -0.5147 & & 0.6 & & 0.146 \\
\hline Others $^{\mathrm{d}}$ & 0 & 1 & & & 0 & & 1 & & \\
\hline \multicolumn{10}{|l|}{ Working experience (years) } \\
\hline$<2$ & 0.4581 & 1.5812 & 0.319 & & 0.0951 & & 1.1 & & 0.826 \\
\hline $2-5$ & 0.1124 & 1.1189 & 0.835 & & -0.2507 & & 0.8 & & 0.625 \\
\hline $6-10$ & 0.0301 & 1.0305 & 0.953 & & 0.0256 & & 1.0 & & 0.957 \\
\hline$>10$ & 0 & 1 & & & 0 & & 1 & & \\
\hline \multicolumn{10}{|l|}{ Current workplace } \\
\hline Hospitals & 0.0205 & 1.0207 & 0.951 & & 0.1644 & & 1.2 & & 0.628 \\
\hline Clinics & 0.4277 & 1.5338 & 0.431 & & 0.9045 & & 2.5 & & 0.039 \\
\hline Laboratory & 0 & 1 & & & 0 & & 1 & & \\
\hline Others $^{\mathrm{e}}$ & 0 & 1 & & & 0 & & 1 & & \\
\hline \multicolumn{10}{|l|}{ Working in Intensive Care Unit } \\
\hline Yes & 0.6628 & 1.9404 & 0.106 & & 0.2788 & & 1.3 & & 0.509 \\
\hline No & 0 & 1 & & & & & 1 & & \\
\hline \multicolumn{10}{|l|}{ Working position } \\
\hline Provide direct healthcare to patients & -0.3897 & 0.6772 & 0.322 & & -0.4995 & & 0.6 & & 0.193 \\
\hline Do not provide direct healthcare to patients & 0 & 1 & & & 0 & & 1 & & \\
\hline \multicolumn{10}{|c|}{ Providing healthcare to COVID-19 patients at workplace } \\
\hline Yes & 0.1018 & 1.1072 & & 0.744 & 0.4396 & & 1.6 & & 0.198 \\
\hline No & 0 & 1 & & & 0 & & 1 & & \\
\hline \multicolumn{10}{|c|}{ Available mental health services at workplace } \\
\hline Yes & -0.3439 & 0.7089 & & 0.255 & -0.3469 & & 0.7 & & 0.265 \\
\hline No & 0 & 1 & & & & & & & \\
\hline \multicolumn{10}{|c|}{ Get support from mental health support team at workplace } \\
\hline Yes & -0.1511 & 0.8596 & & 0.785 & 0.7761 & & 2.2 & & 0.075 \\
\hline No & 0 & 1 & & & 0 & & 1 & & \\
\hline
\end{tabular}

a Participants who had GAD-7 total score of $\geq 10$ are considered to have severe anxiety symptoms.

b Participants who had PHQ-9 total score of $\geq 10$ are considered to have severe depressive symptoms.

c Participants who are widowed, divorced and who never married.

d Others (occupation) included medical assistants, laboratory technicians, pharmacists, research scientists, etc.

e Others (workplace) included pharmacy, public health office, research institute, medical university, etc.

impact is manifested through anxiety, depression, and risk perception. Depression is closely related to the profession regardless of category (doctor, nurse, or others). Health care workers who did not provide direct care to people suspected or sick with COVID-19 expressed low levels of depression. Similar findings were reported in a systematic review of literature which stated that the mental health problems of health care workers are closely correlated to exposure to COVID-19 patients. $^{30}$ In addition, being a health care worker increases the levels of anxiety and psychological distress in comparison to the general population whose mental health has been affected by the pandemic even though they are not in direct contact with COVID-19 patients. ${ }^{32,33}$ A study found that the lack of mental health support in the workplace is statistically related to moderate levels of anxiety among all health care workers. Anxiety is highest among the young, the age group 41-60 years old, male and married health care workers. Another study found that frontline nurses, female and young healthcare workers reported more severe of all psychological symptoms. ${ }^{34}$ Our results are in accordance with this study for young and frontline workers but, in contrast, in our study male healthcare workers showed more severe symptoms compared to female counterparts.

As seen in Table 2 for the GAD-7 variables, mild (26.9\%) and moderate $(7.2 \%)$ levels of anxiety were expressed by study participants, more prevalent among doctors, nurses, and male healthcare workers. No statistical association $\mathrm{p}=0.096$ was found between levels of anxiety and the availability of a mental health support team in the workplace. Levels of depression found were mild $(23.1 \%)$ to moderate $(12.1 \%)$. Doctors reported higher levels of depression in comparison to nurses. Depression was closely related to occupation, $\mathrm{p}=0.000, \mathrm{p}=0.004, \mathrm{p}=0.010$ and 
the direct care for COVID-19 patients, $\mathrm{p}=0.048$. As is reported from other studies, occupation or working closely with COVID-19 patients increases stress among healthcare workers. In regards to this, our findings do not differ from other studies that focused on the mental health of health care workers during the pandemic. ${ }^{35}$ In addition, another study that used the same tools (PHQ-9 and GAD-7) to measure the levels of psychological distress confirmed similar results. Depression, anxiety, and sleep disorders were observed also among Turkish health care workers during the pandemic, in particular among those caring for COVID-19 patients. ${ }^{36}$ The Albanian version of the 7-item scale of GAD showed high reliability (Cronbach's alpha $=0.866$, Cronbach's Alpha Based on standardized items $=0.872$ ). Also, the internal consistency of depression scale shows a Cronbach's alpha $=0,880$ which confirms high reliability for the Albanian version of the 9-item scale of PHQ-9, Table 2.

The total score of risk perception shows high levels among health care workers for all 6-items. Statistical association was found between occupation ( $p=0.011)$, gender $(p=0.031)$, providing care for COVID19 patients $(\mathrm{p}=0.011)$ and the availably mental health support in the workplace ( $\mathrm{p}=0.045, \mathrm{p}=0.025, \mathrm{p}=0.038$ ) and different items of risk perception, Table 2 . The Cronbach's Alpha $=0.601$ for risk perception shows acceptable reliability for this scale. Our results do not differ from a survey that included health care workers from different countries, where the participants expressed high levels of anxiety, depression, and risk perception. ${ }^{37}$ A study carried out in Albania about the attitudes and knowledge of nurses surrounding COVID-19 found that nurses agree that being a healthcare professional increases their likelihood of being infected. The same study also stated that fear of infecting their family members due to their profession was high among nurses. ${ }^{38}$

Table 2 shows a statistically significant association $(\mathrm{p}=0.025)$ between inadequate personal protective equipment for healthcare personnel (PPE) and the availability of mental health support in the workplace. As seen, the risk of getting infected in the workplace is high and produces psychological distress among participants. Similar results were reported by an Italian survey where health care participants expressed high fear of infection due to a lack of adequate protective equipment. The same study also reported sleep disorders among participants. ${ }^{39}$

In the open-ended question surrounding suggested coping strategies, $64 \%$ of participants had no suggestions. $4.4 \%$ suggested receiving mental health support from family, while only $1.5 \%$ respectively suggested support from colleagues or self-support through physical activity, positive thinking, and trusted information, Table 2 . The results, similarly to other studies, suggest a pressing need to provide healthcare workers with coping strategies. ${ }^{40,41}$

As shown by Table 3, symptoms of anxiety were associated with age, marital and living status. Symptoms of depression were associated with living status, workplace, and support from the mental health team at the workplace. Specifically being a male, married and in the age groups, $\leq 25$ and $41-60$ is statistically associated with a higher prevalence of anxiety and depression among healthcare workers in the study. The results are in accordance with other similar study, which highlighted the need to address this risk in an effective way. ${ }^{42}$ This statement is also confirmed by a review study that found that health care workers in hospitals are more vulnerable to stress and depression. ${ }^{43}$ In regard to sociodemographic associations, the results of this study align with those of other studies where young health care workers and those working closely with COVID-19 patients expressed higher levels of anxiety and other psychological symptoms. ${ }^{44}$ In terms of anxiety levels, reported percentages between female and male participants differ very little, Table 2, while the difference is more noticeable in both mild $(30.9 \%$ male vs $21.4 \%$ female) and moderate ( $13.2 \%$ male vs $11.8 \%$ female) depression levels. This result does not correspond with those of similar studies. One carried out in Italy in the same period found that the incidence of psychological symptoms was significant in particular among female nurses. ${ }^{45}$ While another study of mostly male participants found that they were less likely to have anxiety compared to female nurses. ${ }^{46}$ The cross-tabulation of socio-demographic characteristics with occupation highlighted a statistically significant association between each of them, except gender, religion, and living status, $p>0.05$. Our findings do not differ from the findings of other studies that emphasize that working in direct contact with COVID-19 patients and the lack of protective equipment increase the fear of infecting family members among health care workers resulting in increased risk for physical and mental problems. ${ }^{47}$

\section{Conclusions}

The impact of the COVID-19 pandemic on mental health among health care workers in Albania is present. The impact is manifested through moderate levels of anxiety, depression, high perceptions of risk, and low levels of coping strategies. Depression is closely related to the profession regardless of category (doctor, nurse, or other). Lack of mental health support in the workplace is statistically related to moderate levels of anxiety among all health care workers in the study. Based on the study results, the provision of mental health services in the workplace for all health care workers with age group focus is an essential coping strategy. For health care workers working with COVID-19 patients, mental health support should be a priority of the healthcare system. Mental health support can improve the mental health status of health care workers and their family members, impacting the quality of health care provided.

\section{Study limitations}

This is the first study to measure the impact of the COVID-19 pandemic on mental health, risk perception, and coping strategies among health care workers in Albania. This can be considered as one of the strengths, because, despite a year having passed since the beginning of the pandemic, there are few scientific studies related to it, and to this topic in particular, in Albania. In addition, this study and its findings confirm that the impact of the pandemic on the mental health of Albanian health workers is present and that needed interventions should be made based on scientific evidence. One limitation is related to the period when the study was conducted, as in that period Albania was under the effect of first wave of pandemic and the number of cases and deaths from COVID-19 among the general population and healthcare workers was low compared to the end of 2020 and the beginning of the year 2021 . Therefore, the increasing number of cases and deaths, as well as the start of the vaccination process of health personnel in different cities of Albania raises the need to address the generalization of findings. Another limitation is connected to the age and gender of participants. Due to the forms being distributed through social media, the mean age of study participants was on the younger side, as they are more familiar with online platforms. The same can be said in regards to gender, with females making up the majority of the participants. The biggest strength of the study remains the provision of scientific evidence on the mental health of heath care workers in Albania and in this regard the study may be considered a reference point for further studies and interventions. Although, Albania is in the third wave of the pandemic there is no published evidence on the impact of the pandemic in the mental health status of health care workers.

\section{Acknowledgments}

We wish to thank all the health care workers for their participations and for making this project possible.

\section{References}

1 WHO. Coronavirus (COVID-19) events as they happen. Retrieved 2020 April 28 https://www.who.int/emergencies/diseases/novel-coronavirus-2019/events-as-the y-happen; 2020. 
2 Zhu N, Zhang D, Wang W, et al. China novel coronavirus investigating and research team. A novel coronavirus from patients with pneumonia in China, 2019. $N$ Engl $J$ Med. 2020;382(8):727-733.

3 Li Q, Guan X, Wu P, et al. Early transmission dynamics in wuhan, China, of novel coronavirus-infected pneumonia. N Engl J Med. 2020;382(13):1199-1207.

4 Huang C, Wang Y, li X, et al. Clinical features of patients infected with 2019 novel coronavirus in Wuhan, China. Lancet. 2020;395:497-506.

5 Lai X, Wang M, Qin C, et al. Coronavirus disease 2019 (COVID-2019) infection among health care workers and implications for prevention measures in a tertiary hospital in wuhan, China. JAMA network open. 2020;3(5), e209666.

6 Ng DL, Goldgof GM, Shy BR, Levine AG, Balcerek J, Bapat SP, Prostko J, Rodgers M Coller K, Pearce S, Franz S, Du L, Stone M, Pillai SK, Sotomayor-Gonzalez A, Servellita V, Martin CSS, Granados A, Glasner DR, Han LM, Truong K, Akagi N, Nguyen DN, Neumann NM, Qazi D, Hsu E, Gu W, Santos YA, Custer B, Green V, Williamson P, Hills NK, Lu CM, Whitman JD, Stramer S, Wang C, Reyes K, Hakim JMC, Sujishi K, Alazzeh F, Pham L, Oon CY, Miller S, Kurtz T, Hackett Jr J, Simmons G, Busch MP, Chiu CY. SARS-CoV-2 seroprevalence and neutralizing activity in donor and patient blood from the San Francisco Bay Area. medRxiv. 2020 May 25. https://doi.org/10.1101/2020.05.19.20107482 [Preprint], 2020.05.19.20107482, Update in: Nat Commun. 2020 Sep 17;11(1):4698. PMID: 32511477; PMCID: PMC7273245.

7 Liu Q, Luo D, Haase JE, et al. The experiences of health-care providers during the COVID-19 crisis in China: a qualitative study. The Lancet. Global health. 2020;8(6): e790-e798.

8 Lai J, Ma S, Wang Y, et al. Factors associated with mental health outcomes among health care workers exposed to coronavirus disease 2019. JAMA network open. 2020; 3(3), e203976.

9 Ayanian JZ. Mental health needs of health care workers providing frontline COVID19 care. JAMA Health Forum. 2020. https://doi.org/10.1001/ jamahealthforum.2020.0397. Published online April 1.

10 Musabelliu Marsela. No. 3 (Al), March 2020. Albania Social Briefing: COVID-19 in Albania: A Country in Curfew and Lockdown. Weekly Briefing. China-CEE-Institute. 27 ISSN; 2020:2560, 1601.

11 Elflein John. COVID-19 cases worldwide as of July 3, 2020, by country. https://www .statista.com/statistics/1043366/novel-coronavirus-2019ncov-cases-worldwide-by -country/; 2020. Accessed July 3, 2020.

12 Elflein John. COVID-19 deaths worldwide as of July 3, 2020, by country. https://www.statista.com/statistics/1093256/novel-coronavirus-2019ncov-death s-worldwide-by-country/; 2020. Accessed July 3, 2020.

13 Kursumovic E, Lennane S, Cook TM. Deaths in healthcare workers due to COVID-19: the need for robust data and analysis. Anaesthesia. 2020;75(8):989-992. Aug.

14 An Y, Yang Y, Wang A, et al. Prevalence of depression and its impact on quality of life among frontline nurses in emergency departments during the COVID-19 outbreak. J Affect Disord. 2020;276:312-315.

15 Temsah MH, Al-Sohime F, Alamro N, et al. The psychological impact of COVID-19 pandemic on health care workers in a MERS-CoV endemic country. Journal of infection and public health. 2020;13(6):877-882.

16 Felice C, Di Tanna GL, Zanus G, Grossi U. Impact of COVID-19 outbreak on healthcare workers in Italy: results from a national E-survey. $J$ Community Health. 2020;45(4):675-683.

17 Cabarkapa S, Nadjidai SE, Murgier J, Ng CH. The psychological impact of COVID-19 and other viral epidemics on frontline healthcare workers and ways to address it: a rapid systematic review. Brain, behavior, \& immunity - health. 2020;8:100144.

18 Thapa B, Gita S, Chatterjee K, et al. Impact of COVID-19 on the mental health of the society \& HCW (healthcare workers): a systematic review. International Journal of Science \& Healthcare Research. 2020;5(2):234-240.

19 Greenberg N, Docherty M, Gnanapragasam S, Wessely S. Managing mental health challenges faced by healthcare workers during covid-19 pandemic. BMJ. 2020;368: m1211. Mar 26.

20 Spoorthy MS, Pratapa SK, Mahant S. Mental health problems faced by healthcare workers due to the COVID-19 pandemic-A review. Asian journal of psychiatry. 2020; 51:102119.

21 Ornell Felipe, Halpern Silvia Chwartzmann, Kessler Felix Henrique Paim, Narvaez Joana, Magalhães Corrêa de. The impact of the COVID-19 pandemic on the mental health of healthcare professionals. Cad Saúde Pública. 2020;36(4), e00063520. Epub April 30.

22 Jansson M, Rello J. Mental health in healthcare workers and the covid-19 pandemic era: novel challenge for critical care. J Intensive \& Crit Care. 2020;6(2):6.

23 Walton M, Murray E, Christian MD. Mental health care for medical staff and affiliated healthcare workers during the COVID-19 pandemic. Eur Heart J: Acute Cardiovascular Care. 2020;9(3):241-247.
24 WHO Health Emergency Dashboard. WHO (COVID-19) homepage. Accessed online on 1 April https://covid19.who.int/region/euro/country/al; 2021.

25 Charan J, Biswas T. How to calculate sample size for different study designs in medical research? Indian J Psychol Med. 2013;35(2):121-126.

26 Spitzer RL, Kroenke K, Williams JB, Löwe B. A brief measure for assessing generalized anxiety disorder: the GAD-7'. Arch Intern Med. 2006;166(10): 1092-1097.

27 Kroenke K, Spitzer RL, Williams JB. The PHQ-9: validity of a brief depression severity measure. J Gen Intern Med. 2001;16(9):606-613.

28 De Brier N, Stroobants S, Vandekerckhove P, De Buck E. Factors affecting mental health of health care workers during coronavirus disease outbreaks (SARS, MERS \& COVID-19): a rapid systematic review. PloS One. 2020;15(12), e0244052.

29 Zaçe D, Hoxhaj I, Orfino A, Viteritti AM, Janiri L, Di Pietro ML. Interventions to address mental health issues in healthcare workers during infectious disease outbreaks: a systematic review. J Psychiatr Res. 2021;136:319-333.

30 De Kock JH, Latham HA, Leslie SJ, et al. A rapid review of the impact of COVID-19 on the mental health of healthcare workers: implications for supporting psychological well-being. BMC Publ Health. 2021;21:104.

31 Muller AE, Hafstad EV, Himmels J, et al. The mental health impact of the covid-19 pandemic on healthcare workers, and interventions to help them: a rapid systematic review. Psychiatr Res. 2020;293:113441.

32 Kamberi F, Jaho J, Mechili EA, Sinaj E, Skendo H. Effect of Covid-19 pandemic on mental health among Albanian people residing in the country and abroad implications for mental care. Arch Psychiatr Nurs. 2020;34(6):507-512. Dec.

33 Mechili EA, Saliaj A, Kamberi F, et al. Is the mental health of young students and their family members affected during the quarantine period? Evidence from the COVID-19 pandemic in Albania. J Psychiatr Ment Health Nurs. 2020. https://doi.org/ 10.1111/jpm.12672. Jul 13.

34 Vizheh Maryam, Qorbani Mostafa, Arzaghi Seyed Masoud, Muhidin Salut, Javanmard Zohreh, Esmaeili Marzieh. The mental health of healthcare workers in the COVID-19 pandemic: a systematic review. J Diabetes Metab Disord. 2020;19(2): 1967-1978. Dec.

35 Kannampallil TG, Goss CW, Evanoff BA, Strickland JR, McAlister RP, Duncan J. Exposure to COVID-19 patients increases physician trainee stress and burnout. PloS One. 2020;15(8), e0237301. Aug 6.

36 Şahin MK, Aker S, Şahin G, Karabekiroğlu A. Prevalence of depression, anxiety, distress and insomnia and related factors in healthcare workers during COVID-19 pandemic in Turkey. J Community Health. 2020;45(6):1168-1177. Dec.

37 Htay MNN, Marzo RR, AlRifai A, et al. Immediate impact of COVID-19 on mental health and its associated factors among healthcare workers: a global perspective across 31 countries. J Glob Health. 2020;10(2), 020381. Dec.

38 Kamberi F, Sinaj E. Nurses role in the covid-19 pandemic, knowledge and attitudes of nursing staff - implications for the future. Thesis. 2020;9(2):165-183.

39 Puci MV, Nosari G, Loi F, Puci GV, Montomoli C, Ferraro OE. Risk perception and worries among health care workers in the COVID-19 pandemic: findings from an Italian survey. Health Care. 2020;8(4):535. Dec 3.

40 Chew NWS, Lee GKH, Tan BYQ, et al. A multinational, multicentre study on the psychological outcomes and associated physical symptoms amongst healthcare workers during COVID-19 outbreak. Aug Brain Behav Immun. 2020;88:559-565, 3.

41 Mehta S, Machado F, Kwizera A, et al. COVID-19: a heavy toll on health-care workers. Lancet Respir Med. 2021. Feb 5:S2213-2600(21)00068-0.

42 Peres D, Monteiro J, Almeida M, Ladeira R. Risk perception of COVID-19 among the Portuguese healthcare professionals and general population. J Hosp Infect. 2020;105 (3):434-437. May 30.

43 Salari N, Hosseinian-Far A, Jalali R, et al. Prevalence of stress, anxiety, depression among the general population during the COVID-19 pandemic: a systematic review and meta-analysis. Glob Health. 2020;16(1):57. Jul 6.

44 Conti C, Fontanesi L, Lanzara R, Rosa I, Porcelli P. Fragile heroes. The psychological impact of the COVID-19 pandemic on health-care workers in Italy. PloS One. 2020;15 (11), e0242538. Nov 18.

45 Gorini A, Fiabane E, Sommaruga M, et al. Mental health and risk perception among Italian healthcare workers during the second month of the Covid-19 pandemic. Arch Psychiatr Nurs. 2020;34(6):537-544. Dec.

46 AlAteeq DA, Aljhani S, Althiyabi I, Majzoub S. Mental health among healthcare providers during coronavirus disease (COVID-19) outbreak in Saudi Arabia. J Infect Public Health. 2020;13(10):1432-1437. Oct.

47 Shaukat N, Ali DM, Razzak J. Physical and mental health impacts of COVID-19 on healthcare workers: a scoping review. Int J Emerg Med. 2020;13:40. 